\title{
Perioperative Use of Levosimendan in Patients with Left Ventricular Systolic Dysfunction Undergoing Cardiac Surgery on Cardiopulmonary Bypass
}

\author{
Gamal Lotfy Abd Elrahman, Mostafa Mohammed Sabra, Amr Soliman Abd Elmageed, \\ Abd Elkader Abd Elrhman Abd Elkader Elbakery* \\ Department of Anesthesia and Intensive Care, Faculty of Medicine, Al-Azhar University \\ *Correspondence author: Abd Elkader Abd Elrhman Abd Elkader Elbakery, Mobile: (+20) 01004581413, \\ E-mail: dr.sparklight@ hotmail.com
}

\begin{abstract}
Background: Patients undergoing cardiac surgery are becoming older and with greater comorbidities, carrying an increased risk for perioperative complications, which result in higher mortality and higher costs for the health care service. Objective: Our study is randomized, double-blind, placebo-controlled, multicenter clinical study to evaluate the efficacy of levosimendan given preoperatively in high-risk patients with Left ventricular ejection fraction (LVEF) $\leq 35 \%$ undergoing cardiac surgery on cardiopulmonary bypass (CPB).

Patients and methods: This study was carried out in Cardiothoracic Department, Natinaol Heart Institute, Al Hussin hospital, Air Forced Specialized Hospital, and Saudi German Hospital. 60 patients treated with study drug were enrolled, the study population was drawn from patients with an LVEF $\leq 35 \%$ scheduled to undergo cardiac surgery with planned CPB. Results: Our results showed that the relative risk for postoperative mortality at 60 days was reduced by $10 \%$ in the levosimendan group when compared with the control group [4 of $30(13 \%)$ in the levosimendan group vs 7 of $30(23 \%)$ in the control group] with p value $=0.5$, however the incidence of 30-day out-of-hospital complications was not statistically different between the two groups. In the levosimendan group, no significant reduction in the rate of renal replacement therapy was observed [7 of $30(23.3 \%)$ in the levosimendan group vs 8 of $30(26.7 \%)$ in the control group].

Conclusion: Levosimendan is safe and well tolerated in patients undergoing cardiac surgery with cardiopulmonary bypass who have low LVEF and are at risk of the development of postoperative low cardiac output syndrome (LCOS).
\end{abstract}

Keywords: Levosimendan, Left Ventricular Systolic Dysfunction, Cardiac Surgery, Cardiopulmonary Bypass.

\section{INTRODUCTION}

Low cardiac output syndrome (LCOS) is generally more common among patients with impaired left ventricular function, and is managed with inotropic agents and, eventually, mechanical support such as intra-aortic balloon pump, extracorporeal membrane oxygenator or ventricular assist devices. Although recent advances in pharmacologic and mechanical treatments, short-term mortality risk for patients with LCOS remains up to 15 times higher compared to an uneventful postoperative course ${ }^{(\mathbf{1})}$.

Most of the available inotropic agents have detrimental side effect or have a poor safety profile, thus exposing the patient to treatment-related risks and complications. The prevention and the effective treatment of LCOS is one of the pivotal requirement to improve outcomes in cardiac surgery, as preoperative reduced left ventricular function was recognized as the main risk factor for LCOS ${ }^{(2)}$.

Also perioperative myocardial dysfunction is associated with organ failure, prolonged intensive-care stay, delayed recovery and prolonged hospital admissions ${ }^{(3)}$.

Postoperative acute kidney injury can be part of cardiorenal syndrome, which is a classic example of organ dysfunction that can arise due to hypoperfusion, which triggers a sympathoadrenergic response, hyperglycemia and inflammation (4). Phosphodiesterase inhibitors, like milrinone, do the same by inhibiting cAMP degradation, this results in increased cellular energy demands and oxygen consumption, can trigger arrhythmias and can even be cardiotoxic ${ }^{(5)}$.

Inotropic support is frequently initiated in the perioperative period to improve post-bypass ventricular function. However, inotropes include the potential risk of increased myocardial oxygen consumption, which can result in cardiac ischemia, with subsequent damage to hibernating but viable myocardium, and arrhythmias. This prompted a debate on the potential harm associated with inotropic therapy in cardiac surgery. Indeed, the use of perioperative and postoperative inotropes was found to be associated with increased mortality and major postoperative morbidity. Levosimendan is considered to be the ideal inotropic agent to support cardiac function in case of LCOS after cardiac surgery. Levosimendan is a calcium-sensitizing inotrope with a peripheral vasodilatory effect related to the ATP-sensitive potassium channel opening, and is able to increase cardiac output with minimal increase in myocardial oxygen consumption ${ }^{(6)}$.

The effects of levosimendan as an inodilator are based on a triple mechanism of action that provides positive inotropy with a neutral effect on oxygen consumption, and with preconditioning, cardioprotective, anti-stunning and anti-ischemic effects ${ }^{(7)}$. 


\section{AIM OF THE WORK}

Our study is randomized, double-blind, placebo-controlled, multicenter clinical study to evaluate the efficacy of levosimendan given preoperatively in high-risk patients with $\mathrm{LVEF} \leq 35 \%$ undergoing cardiac surgery on CPB.

\section{PATIENTS AND METHODS Study objectives}

The primary objectives are to assess the effect of levosimendan on the incidence of renal replacement therapy through day 30 or postoperative MI or needing of mechanical assist device (IABP, extracorporeal membrane oxygenator) through day 5 , and the incidence of death through postoperative day 60 .

Secondary objectives are postoperative length of intensive care unit (ICU) stay, in hospital complication, out of hospital complication through day 30 and incidence of LCOS and effect on cardiac function, and postoperative use of inotropes through day 5.

Study sites and patient population.

This study was carried out in Cardiothoracic Department Natinaol Heart Institute, Al Hussin Hospital, Air Forced Specialized Hospital, and Saudi German Hospital. 60 patients were enrolled from patients with an LVEF $\leq 35 \%$ scheduled to undergo cardiac surgery with planned CPB.

Ethical approval and written informed consent:

An approval of the study was obtained from Al- Azhar University academic and ethical committee. Every patient signed an informed written consent for acceptance of the operation.

\section{Randomization and study drug administration}

The patients were randomly assigned, in a simple randomization scheme without stratification in a 1:1 ratio to receive either levosimendan or a blinded matching placebo.

Levosimendan (or placebo) infusion was started after insertion of an arterial line and before skin incision at a dose of $0.2 \mu \mathrm{g} \mathrm{kg} / \mathrm{min}$ for the first hour and then reduced to $0.1 \mu \mathrm{g} \mathrm{kg} / \mathrm{min}$ to be continued for another 23 hours (total infusion time of 24 hours).

Main criteria for inclusion and exclusion:

Male and female patients who met the following criteria were enrolled:

\section{Main inclusion criteria:}

- Age $\geq 18$ y.

- Scheduled coronary artery bypass grafting

(CABG), $\mathrm{CABG}$ with aortic valve, $\mathrm{CABG}$ with

mitral valve or isolated mitral valve surgery with or without other valves.

- Surgery using cardiopulmonary bypass (CPB) pump.
- LVEF $\leq 35 \%$ measured by echocardiogram, nuclear scan, or magnetic resonance imaging measured at any time within 30 days before surgery.

\section{Main exclusion criteria:}

- Restrictive or obstructive cardiomyopathy, constrictive pericarditis, restrictive pericarditis, pericardial tamponade, or other conditions in which cardiac output is dependent on venous return.

- Evidence of systemic bacterial, systemic fungal, or viral infection within $72 \mathrm{~h}$ before surgery.

- Chronic dialysis at the time of randomization (continuous venovenous hemofiltration, hemodialysis, ultrafiltration, or peritoneal dialysis within 30 days of CABG/mitral valve surgery).

- Estimated glomerular filtration rate $30 \mathrm{~mL} / \mathrm{min}$ per $1.73 \mathrm{~m}^{2}$ before CABG/valve surgery.

- Weight $\geq 150 \mathrm{~kg}$.

- Patients whose systolic blood pressure (SBP) cannot be managed to ensure SBP $90 \mathrm{mmHg}$ at initiation of study drug.

- Heart rate $\geq 120$ beats/min, persistent for at least 10 min at screening and unresponsive to treatment.

- Hemoglobin $8 \mathrm{~g} / \mathrm{dL}$ within $4 \mathrm{~h}$ before baseline.

- Serum potassium $<3.5$ or $>5.5 \mathrm{mmol} / \mathrm{L}$ at baseline.

- Mechanical assist device (IABP, extracorporeal membrane oxygenation [ECMO]) placed at the start of surgery or preplanned to be placed during CABG/valve surgery before coming off the pump.

- Patients with aortal femoral occlusive disease that would prohibit use of IABP and VAD and ECMO not available.

- Liver dysfunction with Child Pugh class B or C.

- Patients having severely compromised immune function.

- Pregnant, suspected to be pregnant, or breastfeeding.

- Known allergic reaction or sensitivity to levosimendan or excipients.

- A history of torsade de pointes.

- Received commercial levosimendan within 30 days before the planned start of study drug.

- Received an experimental drug or used an experimental medical device within $30 \mathrm{~d}$ before the planned start of study drug.

\section{Data collection:}

Patient information including demographics, medical history, physical examination, electrocardiogram (ECG) results, laboratory results, surgical procedural details,

\section{Clinical follow up:}

Patients were followed up clinically through postoperative day 30 and called at day 60 for ascertainment of vital status.

\section{1) Postoperative myocardial infarction}

Blood samples for creatine kinase (CK), CKMB) were collected and sent to the local laboratory for screening, within 8 hours before surgery, and at 
24, and 48 hours, and day 3, 4 and day 5 after surgery.

Additional samples were drawn if clinically indicated for ischemic symptoms or for new-onset atrial fibrillation and ventricular arrhythmias.

An ECG was be recorded after surgery on days $0,1,2,3$, and 5 , and on the day of and the day after the event for any new ischemic event through day 30.

MIs (through day 5) were defined as CK-MB $100 \mathrm{ng} / \mathrm{mL}$ (or CK-MB 10× upper limit of normal) irrespective of ECG changes, or CK-MB $50 \mathrm{ng} / \mathrm{dL}$ (or CK-MB $5 \times$ upper limit of normal) with evidence of new $Q$ waves $30 \mathrm{~ms}$ in 2 contiguous leads, or new left bundle-brunch block.

\section{2) Postoperative renal impairment and replacement therapy:}

Renal replacement therapy included hemodialysis or other forms of dialytic support including peritoneal dialysis, or continuous venovenous hemodialysis.

\section{3) Using of mechanical assist devices:}

Mechanical assist device use included use of an IABP, extracorporeal membrane oxygenator.

\section{4) Low cardiac output syndrome:}

Low cardiac output syndrome is defined as cardiac index $2.4 \mathrm{~L} \mathrm{~min} / \mathrm{m}^{2}$ for 30 minutes despite optimal fluid balance and maximal inotropic support (dobutamine, milrinone, epinephrine, norepinephrine), with the fluid balance and maximal inotropic dose at the investigator's discretion. Postoperative use of secondary inotrope or vasopressors includes dobutamine, milrinone, epinephrine, or norepinephrine associated with index surgical procedure.

5) ICU length of stay.

6) Seconadry inotropic use more than $24 \mathrm{~h}$.

7) 30 days safty outcome.

On day $30(+5$ days $)$, patients were contacted by phone to collect information about survival status, postoperative MI (days 6-30), or postoperative dialysis beyond discharge up to 30 days.

In addition, information regarding rehospitalization at 30 days along with days and cause of rehospitalization was also obtained.

\section{8) 60 day survival state.}

On day 60 (+5 days), patients will be contacted by phone to determine survival status.

\section{Statistical Methods}

Data were analyzed using IBM@ SPSSC Statistics version 23 (IBMC Corp., Armonk, NY).

Continuous numerical variables were presented as mean and SD and inter-group differences were compared using the unpaired t-test.

Categorical variables were presented as number and percentage and differences were compared using Fisher's exact test.

Two-sided p-values $<0.05$ were considered statistically significant.

\section{Results}

Table (1): Demographic characteristics of both study groups

\begin{tabular}{||l|l|l|l||}
\hline Variable & $\begin{array}{c}\text { Levosimendan } \\
(\mathbf{n = 3 0})\end{array}$ & $\begin{array}{c}\text { Control } \\
(\mathbf{n = 3 0})\end{array}$ & $\begin{array}{c}\text { P- } \\
\text { value* }^{*}\end{array}$ \\
\hline \hline Gender & $15 / 15$ & $14 / 16$ & $1.0 \#$ \\
$(\mathrm{M} / \mathrm{F})$ & & $49.3 \quad \pm$ & 0.648 \\
\hline Age & $50.9 \pm 14.6$ & 12.4 & \\
$($ years $)$ & & $34.9 \quad \pm$ & 0.168 \\
\hline BMI & $31.6 \pm 4.9$ & 12.0 & \\
$\left(\mathrm{~kg} / \mathrm{m}^{2}\right)$ & & & \\
\hline
\end{tabular}

Data are ratio or mean \pm SD.

*Unpaired t-test unless indicated.

\#Fisher's exact test.

This table shows no significant difference between Demographic characteristics among the studied groups.

Table (2): $\quad$ Average hemodynamic variables during $1^{\text {st }} 24$ hours after surgery in both study groups

\begin{tabular}{||l|l|l|l|l|l||}
\hline & \multicolumn{2}{|l|}{ Levosimendan $(\mathrm{n}=30)$} & \multicolumn{2}{l|}{ Control $(\mathrm{n}=30)$} & \\
\hline Variable & Mean & $\mathrm{SD}$ & Mean & SD & P-value* \\
\hline \hline $\mathrm{HR}(\mathrm{bpm})$ & 97.0 & 16.3 & 102.0 & 11.0 & 0.173 \\
\hline $\mathrm{MAP}(\mathrm{mmHg})$ & 74.4 & 16.3 & 63.7 & 13.0 & $<\mathbf{0 . 0 0 7}$ \\
\hline $\mathrm{CVP}\left(\mathrm{cmH}_{2} \mathrm{O}\right)$ & 12.8 & 3.8 & 13.1 & 2.3 & 0.744 \\
\hline Serum lactate $(\mathrm{mmol} / \mathrm{l})$ & 4.3 & 3.9 & 8.8 & 3.0 & $<\mathbf{0 . 0 0 1}$ \\
\hline $\mathrm{SvO}_{2}(\%)$ & 59.8 & 8.7 & 50.4 & 7.7 & $<\mathbf{0 . 0 0 1}$ \\
\hline $\mathrm{CO}_{2}$ gap $(\mathrm{mmHg})$ & 5.2 & 2.3 & 5.6 & 2.7 & $\mathbf{0 . 0 3 2}$ \\
\hline $\mathrm{SV}(\mathrm{ml})$ & 64.7 & 12.1 & 55.7 & 12.1 & 0.05 \\
\hline $\mathrm{CO}(\mathrm{l} / \mathrm{min})$ & 5.2 & 1.4 & 4.5 & 0.8 & $\mathbf{0 . 0 0 9}$ \\
\hline $\mathrm{EF}(\%)$ & 35.1 & 8.8 & 26 & 9.1 & $\mathbf{0 . 0 4 4}$ \\
\hline
\end{tabular}

Data are mean and standard deviation (SD). 
There was a statistical significant difference between the studied groups in serum lactate level, venous saturation, $\mathrm{CO}_{2}$ gap, stroke volume, cardiac output, mean arterial blood pressure and left ventricular function in the first $24 \mathrm{hr}$ after surgery.

Table (3): Urine output in $1^{\text {st }} 5$ days after surgery in both study groups

\begin{tabular}{||c|l|l|l|l|l|l||}
\hline & & \multicolumn{2}{|c|}{ Levosimendan $(\mathbf{n}=\mathbf{3 0})$} & \multicolumn{2}{c|}{ Control $(\mathbf{n}=\mathbf{3 0})$} & \\
\hline Variable & \multicolumn{1}{|c|}{ Time } & \multicolumn{1}{|c|}{ Mean } & SD & Mean & SD & P-value* \\
\hline \hline \multirow{3}{*}{ UOP (ml/24 h) } & Day 1 & 1695.0 & 577.5 & 1513.3 & 282.5 & 0.129 \\
\cline { 2 - 7 } & Day 2 & 2413.3 & 856.5 & 2086.7 & 590.0 & 0.091 \\
\cline { 2 - 7 } & Day 3 & 2526.7 & 1029.4 & 2161.7 & 881.3 & 0.146 \\
\cline { 2 - 7 } & Day 4 & 2651.7 & 1205.9 & 2276.7 & 1150.8 & 0.223 \\
\cline { 2 - 7 } & Day 5 & 2465.0 & 1305.4 & 2126.7 & 1280.3 & 0.315 \\
\hline
\end{tabular}

Data are mean and standard deviation (SD). *Unpaired t-test.

This table shows no significant difference regarding urine output in $1^{\text {st }} 5$ days after surgery in both study groups.

Table (4): Serum creatinine in $1^{\text {st }} 5$ days after surgery in both study groups

\begin{tabular}{||c|c|l|l|l|l|l||}
\hline & & \multicolumn{2}{|c|}{ Levosimendan $(\mathbf{n}=30)$} & \multicolumn{2}{c|}{ Control $(\mathbf{n}=30)$} & \\
\hline Variable & Time & Mean & SD & Mean & SD & P-value* \\
\hline \hline \multirow{3}{*}{ Serum creatinine $(\mathrm{mg} / \mathrm{dl})$} & Day 1 & 1.6 & 0.5 & 1.7 & 0.4 & 0.463 \\
\cline { 2 - 9 } & Day 2 & 1.6 & 0.8 & 1.8 & 0.7 & 0.314 \\
\cline { 2 - 8 } & Day 3 & 1.9 & 1.3 & 1.9 & 0.9 & 0.890 \\
\cline { 2 - 8 } & Day 4 & 2.0 & 1.6 & 2.1 & 1.4 & 0.714 \\
\cline { 2 - 7 } & Day 5 & 1.9 & 1.9 & 2.1 & 1.7 & 0.603 \\
\hline
\end{tabular}

Data are mean and standard deviation (SD). *Unpaired t-test.

This table shows no significant difference regarding Serum creatinine in $1^{\text {st }} \mathbf{5}$ days after surgery in both study groups.

Table (5): Cardiac index in $1^{\text {st }} 5$ days after surgery in both study groups

\begin{tabular}{|c|c|c|c|c|c|c|}
\hline & & \multicolumn{2}{|c|}{ Levosimendan $(\mathbf{n}=30)$} & \multicolumn{2}{|c|}{ Control $(n=30)$} & \multirow[b]{2}{*}{ P-value* } \\
\hline Variable & Time & Mean & SD & Mean & SD & \\
\hline \multirow[t]{5}{*}{$\mathrm{CI}\left(\mathrm{l} / \mathrm{min} / \mathrm{m}^{2}\right)$} & Day 1 & 2.6 & 0.4 & 2.3 & 0.5 & 0.017 \\
\hline & Day 2 & 2.7 & 0.6 & 2.5 & 0.5 & 0.161 \\
\hline & Day 3 & 2.8 & 0.6 & 2.5 & 0.6 & 0.117 \\
\hline & Day 4 & 2.9 & 0.7 & 2.7 & 0.7 & 0.327 \\
\hline & Day 5 & 3.0 & 0.7 & 2.8 & 0.7 & 0.238 \\
\hline
\end{tabular}

Data are mean and standard deviation (SD). *Unpaired t-test.

This table shows significant difference in the cardiac index in the first day after surgery.

Table (6): Serum lactate in 1st 5 days after surgery in both study groups

\begin{tabular}{||l|l|l|l|l|l|l||}
\hline \hline & & \multicolumn{2}{l|}{ Levosimendan $(\mathrm{n}=30)$} & \multicolumn{2}{l|}{ Control $(\mathrm{n}=30)$} & \\
\hline Variable & Time & Mean & SD & Mean & SD & P-value* \\
\hline \hline \multirow{5}{*}{ Serum lactate $(\mathrm{mmol} / \mathrm{l})$} & Day 1 & 6.5 & 3.4 & 8.8 & 3.0 & $\mathbf{0 . 0 0 8}$ \\
\cline { 2 - 8 } & Day 2 & 4.3 & 3.9 & 6.6 & 3.3 & $\mathbf{0 . 0 1 8}$ \\
\cline { 2 - 8 } & Day 3 & 3.6 & 3.7 & 4.8 & 3.3 & 0.194 \\
\cline { 2 - 7 } & Day 4 & 3.1 & 3.9 & 4.3 & 4.4 & 0.272 \\
\cline { 2 - 7 } & Day 5 & 3.0 & 4.1 & 3.9 & 4.9 & 0.438 \\
\hline
\end{tabular}

Data are mean and standard deviation (SD). *Unpaired t-test.

This table shows significant difference in the serum lactate in the first and second day after surgery. 
Table (7): $\quad$ Cardiac enzymes in $1^{\text {st }} 5$ days after surgery in both study groups

\begin{tabular}{|c|c|c|c|c|c|c|}
\hline & \multirow[b]{2}{*}{ Time } & \multicolumn{2}{|c|}{ Levosimendan $(\mathrm{n}=\mathbf{3 0})$} & \multicolumn{2}{|c|}{ Control $(n=30)$} & \multirow[b]{2}{*}{ P-value } \\
\hline & & Mean & SD & Mean & SD & \\
\hline \multirow[t]{5}{*}{ CK (IU/l) } & Day 1 & 3094.5 & 2300.8 & 4848.4 & 2604.7 & 0.008 \\
\hline & Day 2 & 2450.0 & 2338.6 & 4491.3 & 3268.2 & 0.007 \\
\hline & Day 3 & 2035.4 & 2545.2 & 3310.6 & 3396.3 & 0.105 \\
\hline & Day 4 & 1303.1 & 1896.2 & 2560.2 & 3623.0 & 0.098 \\
\hline & Day 5 & 1136.1 & 2196.3 & 1553.9 & 2327.9 & 0.478 \\
\hline \multirow[t]{5}{*}{ CKMB (IU/l) } & Day 1 & 163.0 & 137.4 & 265.3 & 140.9 & 0.006 \\
\hline & Day 2 & 203.8 & 419.6 & 188.1 & 126.9 & 0.845 \\
\hline & Day 3 & 94.2 & 138.7 & 166.8 & 151.7 & 0.058 \\
\hline & Day 4 & 58.0 & 100.3 & 123.8 & 113.9 & 0.021 \\
\hline & Day 5 & 48.4 & 114.5 & 90.2 & 105.3 & 0.147 \\
\hline
\end{tabular}

Data are mean and standard deviation (SD).

*Unpaired t-test.

This table shows significant difference in the cardiac enzymes (CK (IU/l) in the first and second day after surgery and significant difference CKMB (IU/l) in the day 1 and day 4.

Table (8): $\quad$ Need and duration of life support in $1^{\text {st }} 5$ days after surgery in both study groups

\begin{tabular}{||l|l|l|l||}
\hline \hline Variable & Levosimendan $(\mathbf{n}=\mathbf{3 0})$ & Control $(\mathbf{n}=\mathbf{3 0})$ & P-value* \\
\hline \hline Need for inotropes & & & \\
\hline Dobutamine & $18(60.0 \%)$ & $19(63.3 \%)$ & 1.000 \\
\hline Noradrenaline & $11(36.7 \%)$ & $21(70.0 \%)$ & 0.019 \\
\hline Adrenaline & $18(60.0 \%)$ & $16(53.3 \%)$ & 0.792 \\
\hline Milrinone & $1(3.3 \%)$ & $5(16.7 \%)$ & 0.195 \\
\hline Inotrope duration (days) & $3.9 \pm 2.9$ & $5.4 \pm 2.7$ & $\mathbf{0 . 0 4 8}$ \\
\hline Need for VAD & & & \\
\hline IABP & $6(20.0 \%)$ & $6(20.0 \%)$ & 1.000 \\
\hline ECMO & $1(3.3 \%)$ & $3(10.0 \%)$ & 0.612 \\
\hline Any typeof VAD & $7(23.3 \%)$ & $9(30.0 \%)$ & 0.492 \\
\hline VAD duration (days) & $4.1 \pm 0.9$ & $3.1 \pm 1.7$ & 0.154 \\
\hline MV duration (days) & $2.7 \pm 3.6$ & $5.3 \pm 6.6$ & 0.063 \\
\hline Need for RRT & $7(23.3 \%)$ & $8(26.7 \%)$ & 1.000 \\
\hline ICU LOS (days) & $6.7 \pm 3.1$ & $9.1 \pm 5.7$ & 0.050 \\
\hline
\end{tabular}

Data are number (n) and percentage (\%).

*Fisher's exact test.

This table shows significant difference in the intropic duration during the 1st 5 days of ICU admission levosimendan duration.

However there was no significant difference regarding needing for pharmacological or mechanical ventrticual support as well as the needing for renal replacement therapy and mechical ventilation time and ICU stay.

Table (9): Sixty-day survival in both study groups

\begin{tabular}{|c|c|c|c|c|c|c|}
\hline & & \multicolumn{2}{|c|}{ Levosimendan $(n=30)$} & \multicolumn{2}{|c|}{ Control $(n=30)$} & \multirow[b]{2}{*}{ P-value* } \\
\hline Variable & & $\mathbf{n}$ & $\%$ & $\mathbf{n}$ & $\%$ & \\
\hline \multirow[t]{2}{*}{ 60-Day survival } & Survived & 26 & $86.7 \%$ & 23 & $76.7 \%$ & \multirow[t]{2}{*}{0.506} \\
\hline & Died & 4 & $13.3 \%$ & 7 & $23.3 \%$ & \\
\hline
\end{tabular}

Data are number (n) and percentage (\%).

*Fisher's exact test.

This table shows no significant difference regarding Sixty-day survival in both study groups. 
ejhm.journals.ekb.eg

\section{DISCUSSION}

Our study was designed to test the hypothesis that levosimendan is effective in improving outcomes of high-risk patients undergoing cardiac surgery with CPB.

High-risk patients were targeted for enrollment because meta-analysis of available studies on levosimendan suggested greater benefits of the drug in this cohort ${ }^{(8)}$. In our study the baseline demographic data were almost equal in both study group with no significant statistical difference between both groups.

Number of male to female was equal in both groups, the body mass index among levosimendan group mean \pm SD $31.6 \pm 4.9$ and control group $34.9 \pm$ 12.0, regarding the age the levosimendan group mean \pm SD $50.9 \pm 14.6$ and in control group $49.3 \pm 12.4$

It was concordant with other international studies like De Hert et $\boldsymbol{a l} .{ }^{(8)}$ who conducted a study enrolling 30 patients evaluating the effects of levosimendan in cardiac surgery patients with poor left ventricular function. They found that there was no difference in body mass index among levosimendan group mean \pm SD $26.3 \pm 3.6$ and conventional group (milrinone) mean \pm SD 26.2 \pm 3.7 .

Regarding preoperative comorbidity and past medical history, our study also showed no significant statistical difference regarding preoperative comorbidities, preoperative medication, hemodynamics, labs, echo finding, as well as the NYHA class of both study groups which showed almost the similarty of basic characters of both study groups. Those comorbid factors are important risk factors for cardiac disease. There was same concern from other international studies about those comorbid factors.

Our study did not seek for certain type of cardiac surgery to be included in the study with variations of types of surgical procedures but as usual the most of the included cases was CABG or valve replacement surgery, with extension of spectrum of surgical procures to different types like bental and other surgeries but without domination of one type over others.

But this is disconcordant with Alvarez et al. ${ }^{(9)}$ who conducted a study enrolling 50 patient evaluating the hemodynamic effects of levosimendan compared with dobutamine in patients with low cardiac output after cardiac surgery. They found that 12 (57\%) patients had CABG operation among levosimendan group while 9 (45\%) patients had CABG among conventional (dobutamine) group.

Additionally, De Hert et al. ${ }^{(8)}$ had stated that 5 patients had CABG among levosimendan group, 4 patients had CABG for conventional (milrinone) group.

It is also disconcordant with Klasnja et al. ${ }^{(10)}$ who conducted a study enrolling 12 patients evaluating the hemodynamic effects of levosimendan for low cardiac output after cardiac surgery. They found that 8 patients had CABG operation while 4 patients had valve operation.

We think this is due to low percentage of valve surgery in other country due to deficiency of main vale pathology, which leads to valve surgery which is rheumatic heart disease, which is more prominent in Egypt.

Aortic cross-clamping and CPB time in both study groups:

In our study, the use of levosimendan pre and early postoperatively was associated with facilitated weaning from bypass machine. The mean \pm SD of cross calming time and total bypass time of levosimendan group was significantly shorter $(65.5 \pm 51.0),(\mathrm{P}=0.03)$ in comparison with control group (98.0 \pm 55.0$)$ while mean \pm SD of cross calming time and total bypass time respectively of control group was (111.5 \pm 44.0$)$, (148 \pm 60.3 ) with $\mathrm{P}=0.02$.

Additionally, in the randomized, double-blind Eriksson et al. ${ }^{(11)}$, in the LEWE study, levosimendan facilitated weaning from $\mathrm{CPB}$ and reduced the need for additional inotropic or mechanical circulatory support in patients with impaired LVEF $(<50 \%)$ undergoing CABG. 60 patients received either levosimendan as a $12 \mathrm{mic} / \mathrm{kg}$ bolus followed by $0.2 \mathrm{mic} / \mathrm{kg} / \mathrm{min}$ infusion, or placebo, started immediately after the induction of anesthesia. They found that levosimendan significantly facilitated primary weaning from $\mathrm{CPB}$ as compared with placebo $(\mathrm{P}=0.002)$. Four patients in the placebo group even failed the second weaning and had to be supported by IABP, as compared with none in the levosimendan group $(\mathrm{P}=0.112)$.

Disconcordant to our result are Gandham $\boldsymbol{e t}$ al. ${ }^{(12)}$, who conducted a study enrolling 60 patients evaluating a comparison of hemodynamic effects of levosimendan and dobutamine in patients undergoing mitral valve repair / replacement for severe mitral stenosis. They that duration of bypass machine was less with conventional group than levosimendan group $88.7 \pm 10.63 \quad$ (min) VS 92.9 $\pm 9.95 \quad$ (min). This discrepancy between their result and our result may be explained by the lower age group recruited to undergo cardiac surgery for mitral valve replacement.

\section{Hemodynamic variables at end of surgery in both study groups}

In our study the heart rate showed no significant statistical difference at all times postoperatively between both groups $\mathrm{P}>0.05$.

This went side by side with De Hert et al. ${ }^{(8)}$ who stated that there was no statistically significant difference in the heart rate at all times postoperatively between both groups $(\mathrm{P}>0.05)$.

Also, Malliotakis et al. ${ }^{(13)}$ stated that there was no significant changes in heart rate postoperatively $(\mathrm{P}>0.05)$. 
In contrast, Gandham et al. ${ }^{(12)}$ showed that there was significant difference in heart rate being higher in the conventional group at mostly all times postoperatively $\mathrm{P}<0.05$. This difference may be due to that they were mainly comparing dobutamine with levosimendan.

In our recent study the mean arterial pressure was statistically significant at $24 \mathrm{hrs}$ postoperatively $\mathrm{P}$ value $<\mathbf{0 . 0 0 7}$ being higher in the levosimendan group than in control group.

This was in agreement with Alvarez et al. ${ }^{(9)}$ who showed that there was significant mean arterial pressure difference between both groups 6, 12, 24, 48 hrs postoperatively $(\mathrm{P}<0.05)$ being higher in the conventional group.

In our study evaluating central venous pressure immediately postoperatively and $24 \mathrm{hrs}$ postoperatively were statistically not significant between both groups; being lower in the levosimendan group.

Our results didn't agree with other studies like, Alvarez et al. ${ }^{(9)}$ who had found significant difference in central venous pressure at $6,12,24,48 \mathrm{hrs}$ postoperatively between both groups with $\mathrm{P}<0.05$. Malliotakis et al. (13) determined that there was significant difference in central venous pressure at 6 , $12,24 \mathrm{hrs}$ postoperatively from baseline levosimendan infusion $\mathrm{P}<0.05$.

Gandham et al. ${ }^{(12)}$ found that there was significant difference in central venous pressure at immediately, $6,12 \mathrm{hrs}$ postoperatively from baseline levosimendan infusion with $\mathrm{P}<0.05$.

Alvarez et al. (9), Gandham et al. (12) and Malliotakis et al. ${ }^{(13)}$ they all found that there were significant reduction in central venous pressure in levosimendan group as a result of reduction in systemic and pulmonary vascular resistance. This variation matched our study.

In the current work we used $\mathrm{CO}_{2}$ gap, mixed venous saturation and serum lactate being an indicator for adequate cardiac output and tissue perfusion. They were highly significant at almost all times postoperatively $\mathrm{P}<0.05$.

In concordance with other studies Alvarez et al. ${ }^{(9)}$ showed significant difference in mixed venous oxygen saturation at $6,12,24,48 \mathrm{hrs}$ postoperatively between both groups with $\mathrm{p}<0.05$.

Malliotakis et al. ${ }^{(13)}$ determined that there was significant difference in mixed venous oxygen saturation at $6,12,24 \mathrm{hrs}$ postoperatively from baseline levosimendan infusion $\mathrm{P}<0.05$.

In contrast to our results, the double blind, randomized trial by Shah et al. (14), tested preoperatively administered levosimendan $200 \mathrm{mic} / \mathrm{kg}$ infusion for 24 $\mathrm{h}$ against placebo for off pump CABG in 50 patients with left ventricular dysfunction (LVEF <30\%). As compared to the control group, the levosimendan- treated patients had maintained hemodynamic with higher cardiac index and PCWP during the operative and early postoperative periods.

Also our result is in concordance with Mehta et al. ${ }^{(1)}$, the study population consisted of 882 patients with low preoperative LVEF (EF, 35\%) undergoing scheduled or urgent cardiac surgery (CABG and/or mitral valve surgery with or without involvement of other valves).

All patients were considered at risk of developing postoperative LCOS. Levosimendan $(0.2 \mathrm{mcg} / \mathrm{kg} / \mathrm{min}$ for 60 minutes, followed by $0.1 \mathrm{mcg} / \mathrm{kg} / \mathrm{min}$ for 23 hours) or placebo was started at the induction of anesthesia to assess whether the drug would decrease the development of LCOS and its detrimental consequences. The study, conducted at 70 sites in Canada and the United States, demonstrated no statistically robust treatment effect on the composite primary end point of death, perioperative myocardial infarction, and need for renal replacement therapy or a mechanical ventricular assist device. However, there were fewer deaths in the levosimendan group: 20/428 (4.7\%) versus $30 / 421(7.1 \%)$, odds ratio $0.64,95 \% \mathrm{CI}$, $0.37-1.13(\mathrm{P}=0.12)^{(1)}$.

In addition, the levosimendan-treated patients experienced statistically significantly fewer LCOS events (78 vs. 108; $\mathrm{P}=0.007$ ) and needed less inotropic support at or beyond 24 hours after initiation of infusion ( 235 vs. $264 ; \mathrm{P}=0.02$ ). Cardiac index also improved more in levosimendan-treated patients (2.9 +0.6 vs. $2.7-+0.7 \mathrm{~L} / \mathrm{min} \mathrm{P}<0.001)$.

In concordance with other studies Lomivorotov $\boldsymbol{e t} \boldsymbol{a l}$. ${ }^{(15)}$ found that Levosimendan was effective in reducing low cardiac output syndrome when compared with placebo [107 of $723(14.8 \%)$ in the levosimendan group vs 207 of 715 (29.0\%) in the placebo group] (RR $=0.40,95 \% \mathrm{CI}=0.22-0.73 ; \mathrm{P}=0.003 ; \mathrm{I} 2=75 \%$; for heterogeneity $=0.003$, with 1438 patients included and 6 RCTs).

Additionally, Levin et al. ${ }^{(16)}$, showed that the preoperative use of levosimendan started $24 \mathrm{~h}$ before surgery, with a loading dose of $10 \mathrm{micg} / \mathrm{kg}$ infusion for $1 \mathrm{~h}$ that was followed by continuous infusion of 0.1 $\mathrm{micg} / \mathrm{kg} / \mathrm{min}$ infusion for $23 \mathrm{~h}$. Levosimendan resulted in well maintained hemodynamic and reduced the incidence of LCOS (low cardiac output syndrome) $(7.1 \%$ vs. $20.8 \%$; $\mathrm{P}$ value $=0.05)$ and of complicated weaning from CPB (2.4\% vs. 9.6\%; P value $=0.05)$.

Supporting our work, Toller et al. ${ }^{(17)}$, had found that administering the drug in the ICU (late postoperative) in the event of LCOS (low cardiac output syndrome) result in unfavorable outcome. However, early treatment reflects better results.

Therefore, levosimendan should not be used as a last resort, and its administration should not be delayed after other drugs/techniques/strategies have failed and organ failure already is present. 
In our study, the early use of levosimendan significantly increased postoperative ejection fraction than the postoperative ejection fraction with the preoperative, intraoperative and early postoperative use of levosimendan $\mathrm{p}=0.001$

In concordance to our results, Ersoy et al. ${ }^{(18)}$ who conducted a retrospective study enrolling 40 patients within 4 groups 10 patient each group (infusion of Levosimendan, applied $12 \mathrm{~h}$ before operation (G1), after induction of anesthesia (G2), during the pump removal (G3) and non-levosimendan group (G4)) evaluating the effect of preoperative uses of levosimendan in patients undergoing coronary artery bypass grafting (CABG, LVEF <30\%). 0.2 $\mathrm{mic} / \mathrm{kg} / \mathrm{min}$ infusion resulted in increase of LVEF and less myocardial damage in the group used levosimendan $12 \mathrm{~h}$ before surgery.

Also, the double blind randomized trial by Shah et al. ${ }^{(14)}$ tested preoperatively administered levosimendan $200 \mathrm{mic} / \mathrm{kg}$ infusion for $24 \mathrm{~h}$ against placebo for off pump CABG in 50 patients with left ventricular dysfunction (LVEF <30\%). As compared to the control group, the levosimendan-treated patients had higher cardiac index and PCWP during the operative and early postoperative periods.

Hand by hand, Leppikangas et al. ${ }^{(19)}$ stated that preoperative levosimendan infusion, in combined aortic valve and coronary bypass surgery, $12 \mathrm{mic}$ bolus for $10 \mathrm{~min}$ followed by $0.2 \mathrm{mic} / \mathrm{kg} / \mathrm{min}$ infusion for $24 \mathrm{~h}$; treatment that was started on the day before surgery resulted in higher cardiac index and stroke volume index with levosimendan for the 4-day postoperative period $(\mathrm{P}<0.05)$. LVEF was maintained in the levosimendan group while the control group showed a decrease LVEF).

Similarly, Reynolds et al. ${ }^{(20)}$, who conducted a prospective randomized double-blind/vs. placebo on 24 cardiac surgical patients evaluating the effect of levosimendan in aortic valve surgery on cardiac performance and recover12 patients each group). Patients received levosimendan $0.2 \mathrm{mic} / \mathrm{kg} / \mathrm{min}$ infusion for $24 \mathrm{~h}$ beginning after the induction of anesthesia. LVEF was maintained with levosimendan but dropped with placebo.

Additionally, Barisin et al. ${ }^{(21)}$, who conducted a study on 24 cardiac surgery patients evaluating the effect of levosimendan as a new strategy during off pump coronary artery bypass grafting; double blind, randomized, placebo controlled trial. They gave levosimendan at a dose of $12 \mathrm{mic} / \mathrm{kg}$ as an infusion for $15 \mathrm{~min}$ before CABG. At $10 \mathrm{~min}$ and $60 \mathrm{~min}$ postinfusion, the cardiac index and the LVEF were significantly higher with levosimendan than with placebo ( $\mathrm{P}=0.018$ each). The stroke volume index was significantly higher for levosimendan at $10 \mathrm{~min}$ $(\mathrm{P}=0.018)$, but not at $60 \mathrm{~min}(\mathrm{p}=0.063)$.
In addition, Barisin $\boldsymbol{e t}$ al. ${ }^{(21)}$, had found a significant increases in cardiac output and LVEF occurred after high-dose $(\mathrm{P}=0.001, \mathrm{P}=0.006)$ and low dose levosimendan $(\mathrm{P}=0.001, \quad \mathrm{P}=0.002)$. Both levosimendan doses produced significant increased stroke volume and decreased systemic vascular resistance.

\section{Sixty-day survival in both study group}

In our study, mortality incidence with use of levosimendan was lower than mortality with control group in the preoperative, use of levosimendan. 4 cases died during the 60 days follow up in levosimendan group while 7 cases died in the control group. The $\mathrm{P}$ value didn't reach the significant value.

In disconcordance with our work, Levin et al. (16), who used preoperative levosimendan in high-risk patients with severe left ventricular dysfunction (LVEF $<25 \%$ ) scheduled for CABG in a randomized, placebo-controlled trial. Levosimendan was started 24 $\mathrm{h}$ before surgery, with a loading dose of $10 \mathrm{micg} / \mathrm{kg}$ infusion for $1 \mathrm{~h}$ that was followed by continuous infusion of $0.1 \mathrm{micg} / \mathrm{kg} / \mathrm{min}$ infusion for $23 \mathrm{~h}$. Overall, 252 patients participated in the study, levosimendan reduced mortality compared to placebo $(3.9 \%$ vs. $12.8 \%$; $P$ value $=0.05)$.

In concordance Landoni et al. (22) administered levosimendan or placebo to cardiac surgery patients, who, according to predefined criteria, developed postoperative LCOS. In total, 1000 patients were scheduled to be included and the primary end point was 30-day mortality. A total of 248 patients received levosimendan and 258 received placebo There was no significant difference in 30-day mortality between the levosimendan and placebo groups: 32 patients $(12.9 \%)$ versus $33(12.8 \%)$.

This variation from our work could be explained by that they were working on large number of study population 880 patients in Mehta et al. (1) study and 200 patients in Lahtinen et al. ${ }^{(23)}$ study.

\section{CONCLUSION}

Despite recent therapeutic and technological advances in cardiac surgery, many patients with reduced LVEF undergoing cardiac surgery on CPB remain at high risk for perioperative adverse outcomes, including LCOS. Currently available options to prevent and/ or treat complications after cardiac surgery, particularly LCOS, lack robust data supporting their efficacy, are not widely available, and can be prohibitively expensive. Data from our study will provide insight into the efficacy, safety, of levosimendan in reducing short-term morbidity and mortality in high-risk patients undergoing cardiac surgery on $\mathrm{CPB}$. 


\section{RECOMMENDATIONS}

Our study, recomended that a prophylactic infusion of levosimendan started immediately before surgery reduces LCOS in a heterogeneous population of cardiac surgery patients with reduced LVEF. This reduces death rate and the needed inotropic support at or beyond 24 hours after initiation of infusion.

\section{REFERENCES}

1. Mehta RH, Leimberger JD, van Diepen $\mathrm{S}$ et al. (2017): Levosimendan in patients with left ventricular dysfunction undergoing cardiac surgery. New England Journal of Medicine, 376(21): 2032-2042.

2. Anderson MB, Goldstein J, Milano C et al. (2015): Benefits of a novel percutaneous ventricular assist device for right heart failure: the prospective RECOVER RIGHT study of the Impella RP device. The Journal of Heart and Lung Transplantation, 34(12): 1549-1560.

3. Shahian DM, O'Brien SM, FilardoG et al. (2009): The Society of Thoracic Surgeons 2008 cardiac surgery risk models: part 3-valve plus coronary artery bypass grafting surgery. Ann Thorac Surg., 88: 43-62.

4. Banfor PN, Preusser LC, Campbell TJ et al. (2008): Comparative effects of levosimendan, OR-1896, OR1855 , dobutamine, and milrinone on vascular resistance, indexes of cardiac function, and $\mathrm{O} 2$ consumption in dogs. American Journal of Physiology-Heart and Circulatory Physiology, 294(1): 238-248.

5. Zeng J, He W, Qu Z et al. (2014): Cold blood versus crystalloid cardioplegia for myocardial protection in adult cardiac surgery: a meta-analysis of randomized controlled studies. Journal of Cardiothoracic and Vascular Anesthesia, 28(3): 674-681.

6. Packer M, Colucci W, Fisher L et al. (2013): Effect of levosimendan on the short-term clinical course of patients with acutely decompensated heart failure. JACC: Heart Failure, 1(2): 103-111.

7. Ouanes-Besbes L, Ouanes I, Dachraoui F et al. (2011): Weaning difficult-to-wean chronic obstructive pulmonary disease patients: a pilot study comparing initial hemodynamic effects of levosimendan and dobutamine. Journal of Critical Care, 26(1): 15-21.

8. De Hert SG, Lorsomradee S, Cromheecke $S$ et al. (2007): The effects of levosimendan in cardiac surgery patients with poor left ventricular function. Anesthesia \& Analgesia, 104(4): 766-773.

9. Alvarez J, Taboada M, J Rodríguez et al. (2005): Hemodynamic effects of levosimendan following cardiac surgery. Rev Esp Anestesiol Reanim, 52: 389394.

10. Klasnja AV, Jakovljevic DG, Barak OF et al. (2013): Cardiac power output and its response to exercise in athletes and non- athletes. Clin Physiol Funct Imaging, 33:201-205.

11. Eriksson HI, Jalonen JR, Heikkinen LO et al. (2009): Levosimendan facilitates weaning from cardiopulmonary bypass in patients undergoing coronary artery bypass grafting with impaired left ventricular function. The Annals of Thoracic Surgery, 87(2): 448454.

12. Gandham R, Syamasundar A, Ravulapalli $\mathrm{H}$ et al. (2013): A comparison of hemodynamic effects of levosimendan and dobutamine in patients undergoing mitral valve repair/replacement for severe mitral stenosis. Annals of Cardiac Anaesthesia, 16(1): 11-16.

13. Malliotakis $P$, Xenikakis $T$, Linardakis $M$ et al. (2007): Hemodynamic effects of Levosimednan for low cardiac output after cardiac surgery: A case series. Hellenic Journal of Cardiology, 48(2):80-8.

14. Shah B, Sharma P, Brahmbhatt A et al. (2014): Study of levosimendanduring off-pumpcoronaryartery bypass grafting in patients with LV dysfunction: a double-blind randomized study. Indian J Pharmacol., 46: 29-34.

15. Lomivorotov VV, Efremov SM, Pokushalov EA et al. (2014): Randomized trial of fish oil infusion to prevent atrial fibrillation after cardiac surgery: data from an implantable continuous cardiac monitor. Journal of cardiothoracic and Vascular Anesthesia, 28(5): 12781284.

16. Levin RL, Degrange MA, Porcile $R$ et al. (2008): The calcium sensitizer levosimendan gives superior results to dobutamine in postoperative low cardiac output syndrome. Revista Española de Cardiología (English Edition), 61(5): 471-479.

17. Toller W, Algotsson L, Guarracino F et al. (2013): Perioperative use of levosimendan: best practice in operative settings. Journal of Cardiothoracic and Vascular Anesthesia, 27(2): 361-366.

18. Ersoy O, Boysan E, Unal EU et al. (2013): Effectiveness of prophylactic levosimendan in high-risk valve surgery patients. Cardiovascular Journal of Africa, 24(7): 260-66.

19. Leppikangas H, Järvelä $K$, Sisto $T$ et al. (2011): Preoperative levosimendan infusion in combined aortic valve and coronary bypass surgery. British Journal of Anaesthesia, 106(3): 298-304.

20. Reynolds HR and Hochman JS (2008): Cardiogenic shock: current concepts and improving outcomes. Circulation, 117(5): 686-697.

21. Barisin S, Husedzinovic I, Sonicki Z, Bradic $\mathbf{N}$, Barisin A and Tonkovic D (2004): Levosimendan in off-pump coronary artery bypass: a four-times masked controlled study. Journal of cardiovascular pharmacology, 44(6):703-708.

22. Landoni G, Lomivorotov VV, Alvaro G et al. (2017): Levosimendan for hemodynamic support after cardiac surgery. New England Journal of Medicine, 376(21): 2021-2031.

23. Lahtinen P, Pitkänen O, Pölönen P et al. (2011): Levosimendan reduces heart failure after cardiac surgery: a prospective, randomized, placebo-controlled trial. Critical Care Medicine, 39(10): 2263-2270. 